\title{
ORGANIZAÇÃO ESCOLAR E SOCIALIZAÇÃO PROFISSIONAL DE PROFESSORES INICIANTES
}

\author{
MARIA NIVALDA DE CARVALHO FREITAS \\ Fundação de Ensino Superior de São João del-Rei \\ nivalda@funrei.br
}

\begin{abstract}
RESUMO
O objetivo deste artigo é apresentar alguns resultados de pesquisa de mestrado que se referem à influência da organização escolar sobre o processo de socialização profissional do professor iniciante. Realizamos o estudo em cinco escolas: duas da zona urbana e três da zona rural de dois municípios de Minas Gerais. Usamos como recursos metodológicos estudo comparativo de entrevistas não-diretivas realizadas com professores iniciantes e antigos, entrevistas dirigidas com os demais profissionais das escolas, observações nas escolas e análise documental. Adotamos, como quadro teórico de referência para nossas análises e interpretações, o conceito de campo de Bourdieu.

PROFESSORES INICIANTES - SOCIALIZACEAO PROFISSIONAL - ORGANIZAÇÃO ESCOLAR
\end{abstract}

\section{ABSTRACT}

SCHOOL ORGANIZATION AND THE PROFESSIONAL SOCIALIZATION OF BEGINNING TEACHERS. This article presents the results of Master's level research on the influence of school organization on the process of socializing beginning teachers. The study was carried out in five schools, two from the urban and three from the rural areas of two municipalities in the state of Minas Gerais. The methodological tools used were the comparative study of non directive interviews realized with beginning and seasoned teachers; directed interviews with other school professionals; observation in the schools and document analysis. Bourdieu's concept of field was adopted as the theoretical reference for our analyses and interpretations.

Este artigo é parte do original que apresentei como dissertação de mestrado, no Departamento de Educação da Pontifícia Universidade Católica do Rio de Janeiro, em julho de 2000, com o título O professor iniciante e suas estratégias de socialização profissional, sob a orientação da professora Menga Lüdke. 
Entendemos que o processo de socialização profissional constitui-se na aprendizagem dos valores, crenças e formas de concepção do mundo próprios de uma determinada cultura ocupacional. Esse processo pode ser identificado com a aquisição de um ethos profissional, tácito, não necessariamente expresso em palavras, que dá ao agente em socialização o sentido do jogo, isto é, oferece-lhe as condições necessárias para discriminar como deve se portar e atuar, qual o grau de tolerância do grupo profissional para com as diferenças e divergências, que expectativas profissionais pode alimentar, que questões podem ser explicitadas, quando, como e a quem se dirigir, o que deve ser valorizado e o que deve ser esquecido ou, pelo menos, não problematizado explicitamente. Contudo, o processo de socialização não ocorre de forma linear, através de uma incorporação progressiva dos valores do grupo de pertencimento, nem o agente socializado é objeto passivo dos agentes e condições socializadoras. Consideramos, então, que, para a compreensão do processo de socialização profissional, é necessário levar em conta tanto a história do professor iniciante, suas expectativas e projetos quanto as características do grupo profissional a que irá pertencer.

Neste artigo, apresentaremos algumas constatações de nossa pesquisa para o mestrado que se referem às influências da organização escolar sobre o processo de socialização do professor iniciante' e que se constituem em um desdobramento das pesquisas de Lüdke (1996a, I 996b, 1997, 1998; Lüdke, Mediano, 1994) sobre o tema.

Buscando dar conta do problema proposto, utilizamos o conceito de campo de Bourdieu (1996, 1996a, 1998, 1998a) como um esquema heurístico para examinar algumas condições de produção de socialização profissional de professores iniciantes.

Partindo do pressuposto de que a socialização profissional ocorre na articulação entre o agente em socialização e o meio profissional ao qual pretende se filiar, é

I. Para efeitos desta pesquisa, consideramos professores iniciantes aqueles que estejam há, no máximo, seis anos em exercício profissional. A justificativa para a escolha desse intervalo de tempo é referendada por Huberman (1995). Em seu artigo sobre "O ciclo de vida profissional dos professores", ele nos ajuda a compreender as várias etapas pelas quais passaria o professor durante sua carreira profissional. As duas primeiras fases - "a entrada na carreira" e a "fase de estabilização" - contemplam o período de socialização profissional dos professores. A primeira fase é marcada pelo que denomina choque de realidade ou etapa de sobrevivência; e a segunda é descrita como aquela em que o professor interioriza seu papel e constrói uma identidade profissional mais delineada, sendo reconhecido pelos outros como professor. 
necessário compreender tanto as estratégias e interações dos agentes quanto o espaço em que esse processo ocorre. Conforme Bourdieu:

.... proveito científico que se retira de se conhecer o espaço em cujo interior se isolou o objeto estudado (por exemplo, uma dada escola) e que se deve tentar apreender, mesmo grosseiramente, ou ainda, à falta de melhor, com dados de segunda mão, consiste em que, sabendo-se como é a realidade de que se abstraiu um fragmento e o que dela se faz, se pode pelo menos desenhar as grandes linhas de força do espaço cuja pressão se exerce sobre o ponto considerado [...]. E, sobretudo, não se corre o risco de procurar (e de "encontrar") no fragmento estudado mecanismos ou princípios que, de fato, Ihe são exteriores, nas suas relações com outros objetos. (1998a, p. 31-32)

Podemos compreender o campo como uma rede de relações objetivas entre posições. Cada posição só pode ser definida por sua relação objetiva com outras posições, isto é, só se podem apreender as características de uma posição através de sua relação com as demais posições daquele espaço social. Todas as posições dependem de sua situação atual e potencial na estrutura de distribuição de poder (tipo e volume de capital), cuja posse determina a obtenção de lucros específicos. Os campos possuem objetivos específicos e uma lógica particular de funcionamento e estruturação. Possuem uma hierarquia interna, espaços de relações objetivas entre posições, objetos de disputa e interesses particulares, sistema de referências comum definido como espaço de possíveis ${ }^{2}$ e um sistema particular de valoração e distribuição diferente de tipos e volumes de capitais entre os agentes situados em diversas posições no espaço social (Bourdieu, 1996, 1996a).

Assim, tentar compreender como se estrutura a escola, que posição o professor iniciante ocupa, ou poderia ocupar, em que situação se encontra dentro da estrutura de poder da escola, quais os espaços possíveis de investimento que ela oferece, qual ou quais os princípios de diferenciação que funcionam como princípio de distinção entre os professores e como esse campo de forças e de lutas entre as posições contribui para a manutenção ou transformação social, ofere-

2. "Espaço das tomadas de posição realmente efetuadas tal como ele aparece quando é percebido através das categorias de percepção constitutivas de certo habitus, isto é, como um espaço orientado e prenhe das tomadas de posição que aí se anunciam como potencialidades objetivas, coisas 'a fazer', 'movimentos' a lançar, revistas a criar, adversários a combater, tomadas de posição estabelecidas a 'superar' etc." (Bourdieu, 1996a, p. 265). 
ceu-nos pistas importantes para compreendermos como se estrutura a carreira do professor iniciante.

\section{METODOLOGIA}

Com base no aporte teórico, anteriormente descrito, decidimos trabalhar com professores iniciantes que atuassem nos quatro primeiros anos do ensino fundamental. Essa escolha se deve ao fato de esses professores sofrerem maior exposição às pressões da organização escolar, uma vez que trabalham todos os dias, durante pelo menos quatro horas dentro do estabelecimento escolar.

Constatamos que a noção de campo não é um instrumento teórico para ser considerado em si mesmo, mas um conceito que orienta as opções metodológicas da pesquisa. A primeira premissa para a utilização desse conceito é a necessidade de pensar relacionalmente. Era necessário considerar que "o objeto em questão não está isolado de um conjunto de relações de que retira o essencial de suas propriedades" (Bourdieu, 1998a, p. 27). Decidimos, então, operar conforme os procedimentos indicados pelo autor:

Para isso, sugiro-vos o recurso a esse instrumento de construção do objeto, simples e cômodo, que é o quadro dos caracteres pertinentes de um conjunto de agentes ou de instituições: [...] inscreve-se cada uma das instituições em uma linha e abre-se uma coluna sempre que se descobre uma propriedade necessária para caracterizar uma delas, o que obriga a interrogação sobre a presença ou ausência dessa propriedade em todas as outras - isto, na fase puramente indutiva da operação; depois, fazem-se desaparecer as repetições e reúnem-se as colunas que registram características estrutural ou funcionalmente eqüivalentes, de maneira a reter todas as características - e essas somente - que permitem discriminar de modo mais ou menos rigoroso as diferentes instituições, as quais são, por isso mesmo, pertinentes. Este utensílio, muito simples, tem a faculdade de obrigar a pensar relacionalmente tanto as unidades sociais em questão como as suas propriedades, podendo estas ser características em termos de presença ou de ausência (sim/não).

Mediante um trabalho de construção dessa natureza - que se não faz de uma só vez mas por uma série de aproximações - constroem-se, pouco a pouco, espaços sociais os quais - embora não só se ofereçam em forma de relações objetivas muito abstratas e se não possa tocá-los nem apontá-los a dedo - são o que constitui toda a realidade do mundo social. (1998a, p. 29-30)

Usamos como estratégia metodológica o estudo comparativo de entrevistas não-diretivas realizadas com 13 professores iniciantes e 16 professores antigos em 
cinco escolas de ensino fundamental: duas da zona urbana e três da zona rural, em dois municípios mineiros. Essas entrevistas buscavam explorar a questão de como pensavam sobre ou se sentiam em relação ao início de suas carreiras como professor, da forma como julgassem mais conveniente, mesmo que trouxessem elementos que em princípio parecessem fora do campo proposto.

Quanto à análise das entrevistas, privilegiamos o discurso dos entrevistados, por isso gravamos e depois transcrevemos todas as entrevistas realizadas. Segundo Michelat (1987), a análise interpretativa só é possível se pudermos manter a lógica do entrevistado, isto é, o sistema de relações por ele estabelecido. Então, durante o processo de análise das entrevistas, buscamos apreender a lógica própria de cada entrevistado, visando identificar os temas que eram recorrentes em cada entrevista, que relações o entrevistado fazia entre os temas, quais as principais contradições explicitadas pelo entrevistado e que destino dava a essas contradições. Além disso, demos uma atenção especial aos lapsos e negações, que nos informavam sobre o caráter conflituoso daquelas informações e nos revelavam a carga emocional imprimida nelas.

As entrevistas foram lidas e relidas diversas vezes, buscando alcançar o que Michelat (1987) denominou impregnação. Essas leituras repetidas iam suscitando interpretações que eram possíveis através do relacionamento dos diversos elementos da entrevista. Também foi considerada a possibilidade de divergentes interpretações. Cada vez que isso acontecia, retomávamos o contexto do entrevistado e verificávamos se havia um equívoco de nossa parte ou se a divergência refletia atitudes ambivalentes dos entrevistados em relação à temática pesquisada. Após a análise de cada entrevista, fizemos uma comparação entre todas as entrevistas procurando ir além da análise particular de como cada professor pensa (ou sente) sobre o processo de socialização e compreender os modelos culturais específicos do início da carreira docente.

Outro procedimento adotado foi a realização de entrevistas estruturadas com diretores e pedagogos das escolas visando compreender a identidade atribuída ao professor iniciante, isto é, como ele era percebido e que expectativas existiam em relação ao seu desempenho. Realizamos oito entrevistas dirigidas com outros profissionais das escolas pesquisadas: três diretoras, quatro supervisoras e uma orientadora. Além disso, fizemos algumas observações, principalmente em uma das escolas da zona urbana, das interações entre esses professores e os demais profissionais da escola, em três situações distintas: reuniões (módulos) realizadas semanalmente; conversas informais no horário de café; e momentos 
em que as supervisoras orientavam os professores iniciantes. Fizemos também uma análise dos documentos das escolas que pudessem nos ajudar a caracterizálas melhor.

Quanto às cinco escolas pesquisadas, concentramo-nos nos aspectos funcionalmente eqüivalentes entre elas, buscando ser coerentes com nosso referencial teórico e deixando de lado possíveis discussões sobre suas especificidades, que poderiam revelar aspectos interessantes, mas alheios aos interesses da pesquisa.

\section{DISCUSSÃO DOS RESULTADOS}

Esta discussão está voltada para a busca de configuração de algumas influências da organização escolar sobre o processo de socialização do professor iniciante constatadas nas escolas pesquisadas.

\section{ATRIBUIÇÃO DE TURMAS AOS PROFESSORES}

A partir da análise comparativa das entrevistas, das observações e da análise documental, verificamos que é comum nas escolas pesquisadas delegar ao professor iniciante as turmas consideradas mais difíceis, isto é, aquelas que possuem o maior grau de complexidade, tanto no que diz respeito às estratégias didáticas a adotar quanto no que se refere à disciplina. São turmas marcadas por uma grande diversidade: possuem alunos com níveis de aprendizagem desiguais, que, muitas vezes, não possuem os materiais escolares mínimos e pertencem a famílias de baixo poder aquisitivo. Verificamos, também, que outra estratégia adotada consiste em nomear os professores iniciantes para a zona rural, onde as condições de trabalho das escolas pesquisadas são piores, do ponto de vista da falta de material didático, pequena possibilidade de troca de experiência e acompanhamento pedagógico, delegação de turmas multisseriadas, dificuldade para se conciliar vida profissional e pessoal, uma vez que a maioria dos professores permanece na escola durante toda a semana e as pedagogas só comparecem à escola uma vez por semana.

O início - vou falar a verdade - é decepcionante porque a gente fica sempre com aquela última turma da escola. Então, a gente vem com aquela ilusão das didáticas e quando chega na sala de aula, a realidade é outra... sobra aquela turma pesada para você, a decepção é grande. Aí, no dia-a-dia, a gente vai se adaptando, vai fazer o quê? Você tem a necessidade financeira, precisa trabalhar... (Prof. C 4) 
Essa realidade também é apontada em outras pesquisas que focalizam o professor iniciante. Veenman (conforme discussão de Guarnieri, 1996) afirma que um dos fatores que contribuem para o "choque de realidade" em professores iniciantes é o fato de serem alocados para as classes difíceis. Segundo Gonçalves, os professores consideram os piores anos do exercício profissional o início e o final da carreira. Quanto ao meio da carreira, as razões evocadas são: "a colocação, os alunos difíceis, o meio socioeconômico dos alunos, a vida particular, as condições de trabalho e formação" (1995, p. 155). Também para Brandão, Baeta e Rocha "as professoras que ingressam no sistema ficam sempre com as turmas consideradas mais difíceis" (1986, p. 74).

Essa constatação, já enunciada em diversas pesquisas, levou-nos a questionar por que as tarefas mais complexas são destinadas aos iniciantes na profissão de professor. Essa estratégia de divisão de tarefas difere da maioria das profissões exercidas dentro das organizações de trabalho. Muito raramente veremos, dentro de uma empresa, um engenheiro iniciante desempenhando as tarefas mais complexas; elas são sempre destinadas aos engenheiros experientes, sendo, inclusive, um fator de reconhecimento. Também aos médicos iniciantes não é delegado o trabaIho de diagnóstico e tratamento dos quadros clínicos mais complexos; eles, usualmente, encaminham esses pacientes para os médicos mais experientes e com a especialização adequada para aquele tipo de patologia. Os psicólogos, da mesma forma. Também nas outras profissões, as formas de divisão do trabalho não diferem muito dessas.

Buscando compreender que fatores do desempenho do professor eram passíveis de reconhecimento profissional e que características possuía um bom professor nas escolas pesquisadas, reportamo-nos às entrevistas realizadas com as diretoras e supervisoras:

É o professor que sabe entender o aluno, aproveitar o tempo em sala de aula, trabalha de acordo com os temas trazidos pelos alunos, sabe ouvir os pais e é interessado. É dinâmico, faz o aluno se interessar por suas aulas. Muitas vezes, o professor experiente não é o melhor professor. (Diretora da Escola Municipal "Crisântemo")

Os professores tidos como tendo um desempenho deficiente são aqueles que "não dominam o conteúdo, não conseguem manter a disciplina na sala de aula, tratam os alunos com falta de respeito e não se interessam pelas atividades da escola" (Diretora da Escola Municipal "Miosótis"). 
No entender de Cunha (1989) essa definição de bom professor é uma categoria valorativa, estando sujeita a variações tanto em relação ao tempo quanto ao espaço, e ideológica, pois representa uma idéia que é construída socialmente sobre o professor.

Verificamos, também, que essas habilidades atribuídas ao bom professor não se refletem na avaliação formal de seu desempenho. Essa avaliação, segundo informações obtidas das escolas, é um elemento relevante para a progressão horizontal dos professores e conseqüente melhoria salarial. Apesar de nos ter sido informado que, para os professores obterem a progressão horizontal, eles eram submetidos a uma avaliação de seu desempenho, a nenhum dos professores tidos como deficientes pelas escolas foi negada essa progressão. $O$ que foi considerado na avaliação foi o tempo de serviço dos professores, isto é, o interstício de dois anos de trabalho para cada progressão horizontal.

Também para os professores entrevistados, a avaliação de desempenho não se constitui em um fator relevante em suas vidas profissionais. Entre os 29 entrevistados, apenas uma professora iniciante manifestou sua preocupação com o resultado da auto-avaliação que havia feito e da qual ainda Ihe não tinha sido dado nenhum feedback. Os demais não mencionaram a avaliação de desempenho em suas entrevistas. Sua preocupação e também seu objeto de investimento eram a aprendizagem dos alunos, a obtenção dos objetivos propostos no início do ano para a turma com que trabalhavam.

Tomamos a fala de uma das supervisoras como contraponto das considerações das diretoras do que seria uma boa professora:

Quem está começando não tem experiência, logo não é bom. A escola não dá turma boa para os iniciantes porque acha que eles não vão dar conta. A professora que trabalha com turmas difíceis não é considerada boa porque a turma não tem bom rendimento. Na turma boa, com bom rendimento, o professor é considerado bom. Ser bom ou ruim professor passa pelo rendimento da turma. Alguns pais, inclusive, escolhem a professora para seus filhos porque sempre trabalha com turmas boas, que tem bom rendimento. A família contribui para este reconhecimento. Em turma boa, o professor é reconhecido. Dê-me uma turma boa que serei considerada boa professora. (Supervisora da Escola Municipal "Crisântemo")

Devido à sua posição de iniciante e a explicitação de sua insegurança sobre a permanência ou não na escola, essa supervisora nos ajudou a ter acesso às contradições de que são vítimas como iniciantes. Segundo Bourdieu, os ocupantes de posições instáveis são: 
...extraordinários "dispositivos analisadores práticos": situados em pontos onde as estruturas sociais "estão em ação" e, por esse fato, movidos pelas contradições dessas estruturas, eles são obrigados, para viver ou sobreviver, a praticar uma forma de auto-análise que, muitas vezes, dá acesso às contradições objetivas de que são vítimas e às estruturas objetivas que se exprimem através delas. (1998, p. 236)

A fala dessa supervisora, reforçada pelos depoimentos dos professores antigos, tais como "Detesto trabalhar com turmas difíceis"; "Graças a Deus, eu tenho sempre trabalhado com turmas boas"; "Essas turmas difíceis não têm jeito, as crianças não querem saber de estudar, são indisciplinadas, não têm educação"; indica uma forma de classificação utilizada pelas escolas: turma boa e turma difícil. A maioria dos professores antigos (com mais de seis anos de experiência) não quer trabalhar com as turmas consideradas difíceis nem com alunos considerados problema: "Colocar um aluno difícil na turma é a mesma coisa que acabar com a sala" (Prof. MT 8).

Essa forma de atribuição das turmas assegura um maior reconhecimento profissional para os professores antigos, pois eles, além de já terem incorporado o esquema de percepção e pensamento necessários para saber quais objetos oferecidos pela escola são passíveis de investimento e asseguram reconhecimento, têm a oportunidade de escolher as turmas com as quais desejam trabalhar. Aos professores que chegam, essa oportunidade de escolha só será oferecida depois de alguns anos, quando, para obter reconhecimento, irão escolher trabalhar com as turmas boas, o que contribui para se instalarem relações de luta entre eles:

Neste ano quando me falaram para eu ficar com a minha turma, era pré-silábica, é nível de $2^{\circ}$ período praticamente, nem era de uma la série. Eu tinha que vencer os objetivos de $2^{\mathrm{a}}$ série, me cobraram os objetivos da $2^{\mathrm{a}}$ série. Eu assustei muito, para te falar toda verdade, até chorei porque pensei assim: meu Deus, em 16 anos eu trabalhei com essa clientela, agora, depois de pegar uma sala um pouquinho melhor, fiquei entusiasmada, porque nunca tinha trabalhado com uma sala daquele porte, eu voltei. Eu não chorei de susto de enfrentar a situação, porque sempre trabalhei assim e nunca tive medo, porque, graças a Deus, sempre dei conta, lutei para isso. Falei para a diretora e a supervisora que eu estava com um problema no braço, que estou inclusive em tratamento. Daí elas queriam trocar as salas, mas as outras [professoras] já tinham visto as salas que iriam trabalhar. Todas disseram na hora: Eu não troco não. Então, eu decidi ficar com essa turma mesmo, pensei assim, se eu concordar com a mudança: meu Deus, agora vou virar o Cristo da escola, vou ficar antipatizada; elas vão achar que usei o meu problema para ficar com uma sala boa e eu não quero isso. (Prof. MT 6) 
A mensagem dirigida aos professores iniciantes, contudo, é diferente: "Estas turmas são difíceis mesmo, o mínimo que você conseguir já é muita coisa" (Prof. MT I , sobre a orientação dada pela supervisora). Verificamos, também, que a maioria dos professores iniciantes não questiona, pelo menos explicitamente, essa estratégia de distribuição de turmas.

Nas escolas pesquisadas, a diferença de posição entre os professores é determinada pelo tempo de exercício profissional associado à experiência. A questão da qualificação profissional, isto é, a posse de diplomas ou títulos universitários, é um fator de diferenciação para a política salarial e de progressão em apenas uma delas. Essa constatação é confirmada por Lelis:

...para aqueles professores que obtiveram o diploma, o que fica é o poder simbólico desta qualificação em grau superior, mesmo que não chegue a alterar significativamente modos de vida, e mesmo que não corresponda às necessidades do mundo do trabalho. (1997, p. 153)

Também Guarnieri afirma que "os veteranos, entretanto, usualmente obtêm atribuições de ensino mais atraentes e com alunos mais capazes" (1996, p. I 5).

Essa forma de reconhecimento envolve os professores na lógica interna da organização escolar, implícita na configuração da trajetória profissional do professor: primeiro, as turmas mais difíceis quando o professor ainda não tem nenhuma experiência profissional e nas quais o nível de complexidade é maior; além de não haver reconhecimento da escola, nem dos pais, nem da comunidade em geral. Depois, com o tempo e a experiência adquirida, as melhores turmas e os reconhecimentos devidos. Então, legitima-se a crença nos mais capazes. A escola tentou com as crianças das camadas não destinadas ao êxito escolar, mas não conseguiu porque "as crianças não conseguem", segundo as justificativas dos professores antigos e demais profissionais das escolas. E, duplamente, ela também consegue silenciar qualquer crítica interna dos professores, pois há uma distorção na orientação da carreira dos professores logo no início, quando lhe atribuem as turmas mais difíceis no momento em que ainda não dominam as estratégias básicas do manuseio da sala de aula. "Não tem jeito mesmo com essas crianças" (Orientadora da Escola Municipal "Miosótis").

Com o passar do tempo, pode-se dar ao professor a possibilidade de escoIher a turma com a qual deseja trabalhar, e ele não escolherá as turmas mais difíceis, quando, em princípio, estaria mais preparado para recebê-las. $\bigcirc$ objeto de investimento possível para a obtenção de reconhecimento profissional acaba sendo configurado pela escola, ou seja, o trabalho com as melhores turmas. 
Aliadas à maior possibilidade de reconhecimento, as melhores turmas também representam para o professor um desgaste menor e um sofrimento também menor, pois é possível, com as estratégias pedagógicas comumente adotadas pelas escolas, alcançar os melhores resultados com esses alunos.

Essas turmas difíceis desgastam demais a gente. A gente trabalha, trabalha, tenta tudo o que pode, inventa coisas e na maioria das vezes o resultado não é bom. É muito sofrido. Chega no final do ano, a gente está acabada. (Prof. MT 14)

Esses indícios da matriz da trajetória profissional dos professores colocam muitos deles diante das contradições entre seus projetos pessoais, muitas vezes o de trabalhar com as camadas menos favorecidas do ponto de vista econômico, e o sistema de reconhecimento oferecido pelas escolas.

Os professores antigos, aceitando e desejando trabalhar com as melhores turmas, agora escapam das contradições internas e externas que, porventura, poderiam viver. Os poucos que fazem a opção por trabalhar com as turmas difíceis são comumente chamados de "coitados" pelos outros professores e profissionais da escola. Contudo, aqueles entre os quais se incluem vários pesquisados, que, embora desejando o reconhecimento profissional, também gostariam de trabalhar por uma escola voltada para uma transformação social, vivem continuamente essa ambivalência.

Essas formas de classificação dos alunos (turma boa e turma difícil), de diferenciação dos professores (maior ou menor tempo de exercício profissional) e de atribuição das melhores turmas aos professores mais antigos (com o conseqüente reconhecimento profissional pelo trabalho desempenhado) demonstram a política paradoxal dessas organizações: ao mesmo tempo que a escola explicitamente pretende ser uma escola para todos, democrática, implicitamente, impede que seja de fato um lugar para todos, porque o objeto de preferência e reconhecimento continua sendo as melhores turmas. As escolas carregam em si tanto o desejo de uma transformação social quanto as prerrogativas de sua perpetuação.

O produto de tal injunção contraditória da escola, entre um desejo de transformação e uma estratégia inconsciente de perpetuação da estrutura social, não é só a ambivalência do professor em relação a si mesmo, mas também o sentimento de culpa para com os alunos das camadas populares. Aqueles professores que conseguem o reconhecimento da escola, muitas vezes, sentem-se culpados por estar lecionando nas melhores turmas; se trabalham com as turmas mais dificeis, sentemse frustrados perante os resultados obtidos. 
Como pudemos verificar nas entrevistas, a maioria deles, visando escapar do conflito vivenciado devido a essa contradição, utiliza como estratégia defensiva o adiamento da sua resolução para depois da aposentadoria ou para um futuro hipotético, como uma forma de garantir ao mesmo tempo o reconhecimento atual da escola e uma coerência interna com seus projetos profissionais.

Penso assim: se Deus me ajudar, quando eu aposentar, quero me engajar em um trabalho com uma comunidade carente; eu gostaria, tenho vontade. É o único sonho que tenho mesmo é trabalhar numa comunidade carente com crianças. (Prof. MT 7) Um dia desses brincaram comigo aqui, disseram... quem sabe você ganha na sena sozinha e você abre uma escola para você. Falei: Não! Seria uma escola só para criança pobre, porque eu não ia deixar criança que tivesse condições financeiras entrar nela não; elas têm outro jeito na vida, se viram para lá. Eu ia cuidar só de criança que tivesse dificuldade, mas tudo do jeito que eu sonho, entendeu? O magistério para mim é isso, é decepção, mas ao mesmo tempo é muita alegria, amor. Dedico de coração. (Prof. C 6)

Essas professoras são consideradas boas pelas escolas em que trabalham e, normalmente, atuam nas melhores turmas: "Sempre fico com sala boa. Não posso reclamar" (Prof. C 06).

Também a projeção é outra estratégia defensiva utilizada por muitos professores antigos para lidar com os conflitos internos decorrentes da forma de reconhecimento utilizada pela escola:

Também não tem jeito mesmo: essas crianças que estão nas piores turmas sempre vêm de uma estrutura familiar falida, não têm estímulo dentro de casa. Não culpo os pais, porque, muitas vezes, eles também não têm condições de ajudar, nem financeira, nem a formação adequada. E as crianças nem afeto recebem. Eu acho que a escola do jeito que é não funciona para essa clientela da escola pública. Esse modelo é furado. A maioria dos nossos alunos tem problemas com a família. (Prof. MT 16)

Os professores iniciantes, que ainda não assimilaram a lógica interna da escola, diferem dos professores antigos no que diz respeito aos alunos considerados difíceis. Tal fato pode ser constatado na maneira como um e outro se referem aos mesmos. Todos os iniciantes expressaram uma preocupação recorrente:

Não sei o que faço para conseguir a atenção dos alunos. (Prof. MT 3)

Será que estou fazendo da maneira certa, são sempre tentativas e erros. (Prof. MT 2) Eles [as crianças] não têm interesse. É preciso trabalhar com a cabecinha deles. (Prof. C 3) 
Como resolver o problema da disciplina, eu não sei. (Prof. C I)

Precisamos de mais conhecimento para lidar com essas crianças. (Prof. MT I)

No primeiro ano em que trabalhei, todos os meus alunos tomaram bomba; ninguém falou nada, a culpa do fracasso das crianças foi minha, eu não tinha nenhuma experiência. (Prof. $\mathrm{Cl}$ )

As pesquisas realizadas por Lüdke e Mediano confirmam esta constatação:

....as professoras [iniciantes] atribuem a si próprias as dificuldades do processo. Nenhuma delas diz que "as crianças não aprendiam" ou "com aquelas crianças não tinha jeito", como é comum ouvirmos atualmente de grande número de docentes, ao se referirem às crianças de camadas populares. (1994, p. 27-28)

Essa forma de encarar os problemas, por parte do professor iniciante, como responsabilidade apenas sua, apesar de constituir uma dificuldade de esse professor perceber os constrangimentos institucionais que se refletem em seu trabalho (Kuzmic, 1994), também pode ser analisada como um fator que contribui para a sua socialização profissional. Ela faz com que ele lute com todas as suas forças para superar as dificuldades que encontra, desenvolvendo estratégias para conseguir realizar um trabalho melhor e, inclusive, minimizar sua culpa:

Os professores iniciantes não são acomodados, acreditam na educação. Buscam ajuda, normalmente respeitam os alunos, compreendem suas dificuldades. São mais flexíveis, buscam inovar, aplicar algumas coisas que aprenderam durante o curso de magistério em sua sala de aula. Só que muitas vezes não conseguem os resultados que esperavam. Mas sempre estão tentando, apesar de sua insegurança. (Supervisora da Escola Municipal "Crisântemo")

Essa busca de soluções para seus problemas auxilia-o a construir saberes e, com o tempo, ele acaba adquirindo uma segurança maior, uma confiança em si mesmo que extrapola do domínio pessoal para o relacional, passando a ser respeitado também pelos pares e demais profissionais da escola. Ele não capitula, e isso é uma porta aberta para sua construção profissional. Então, ele é acolhido entre seus pares porque foi capaz de passar por essa "prova de iniciação". Podemos considerar esse início de trajetória profissional como perverso, quase como uma utilização instrumental do iniciante para realizar aquele trabalho difícil que não oferece reconhecimento. Mas a forma como o professor iniciante enfrenta esses problemas ajuda-o a vencer suas dificuldades e ser admitido entre os "iniciados", levando-o ao reconhecimento profissional. Depois, provavelmente, quando lhe for dada a oportunidade de escolher 
as turmas, ele não optará pelas mais difíceis, mas ele enfrentou as dificuldades e conseguiu se fazer respeitar por considerar que elas eram um problema seu.

Essa forma, encontrada nas escolas pesquisadas, de conceber a trajetória profissional do professor, oferece-nos pistas sobre algumas condições institucionais de produção de um modo de atuação, percepção, visão e divisão que se impõe ao professor iniciante ao mesmo tempo que propicia o desconhecimento dessas condições. Esse desconhecimento, que se deve à incorporação de percepções adquiridas dentro da organização escolar, seja na socialização antecipatória, seja na formação inicial, seja no exercício profissional. Tais percepções, por serem na maioria das vezes inconscientes, fornecem a matriz não problematizada para se fazerem as apostas dentro da organização, perdendo-se a oportunidade de submetê-la a uma análise de sua produção histórica e institucional.

Tendo por parâmetro de análise essa estratégia comparativa entre os professores antigos e iniciantes, podemos perceber que a escola, embora inconscientemente, impõe injunções contraditórias ao professor iniciante durante seu processo de socialização, através das condições oferecidas para a obtenção do reconhecimento profissional. Isso é resultado de sua própria contradição interna entre procurar ser um instrumento de transformação social e não evitar ser um instrumento de perpetuação da ordem social.

Por outro lado, a participação desses professores iniciantes em outros espaços de formação e mesmo de vida, que mantêm uma certa autonomia em relação à organização escolar em que trabalham, garante-lhes a possibilidade de adotarem uma postura crítica que os auxilia a buscarem saídas para as injunções contraditórias que vivenciam.

\section{A POLÍTICA DE MUNICIPALIZAÇÃO DAS ESCOLAS}

Verificamos que a política de municipalização do governo federal, através da Lei 9.394/96, artigo II , implementada nas duas escolas urbanas pesquisadas, contribuiu para que se instale dentro da organização escolar um novo elemento nas relações de luta entre os professores: a sua proveniência do sistema estadual ou municipal de ensino.

A configuração da organização escolar modificou-se com a reunião, em um mesmo estabelecimento, de professores oriundos do estado e do município. Os professores, de forma consciente ou inconsciente, passaram a desenvolver um conjunto de estratégias para impor uma forma de classificação valorativa, de acordo com sua origem institucional. 
Verificamos que alguns professores do estado compartilhavam as seguintes idéias:

Os melhores professores do município são piores que os professores do estado. Não por culpa deles, mas porque a maior parte de sua experiência foi construída na zona rural, com uma clientela diferente da nossa. (Prof. MT 14)

A educação no município é pouco regulamentada, esbarra na política pessoal e pode haver interferência direta do prefeito nas escolas, através da contratação de professores. No estado, a infra-estrutura é imensa. (Diretora da Escola Municipal "Miosótis" - oriunda do estado)

Por outro lado, ouvimos os professores do município afirmando:

As professoras do estado que já estavam na escola quando ela foi municipalizada não dão nenhuma informação para as professoras do município; não nos informam sobre os materiais disponíveis na escola, sobre a forma como trabalhavam antes, nada. Elas se acham melhor do que a gente. (Prof. MT 3)

A relação entre os professores não é boa. Já melhorou um pouco, mas ainda tem muita separação entre elas. As professoras do estado se acham melhor que as do município e, muitas vezes, é até o contrário. (Supervisora da Escola Municipal "Miosótis" - oriunda do município)

A forma de atribuição de turmas no início do ano foi objeto de disputa em uma das escolas municipalizadas (Escola Municipal "Miosótis"). A diretora, tentando administrar essa disputa entre as professoras do estado e do município pelas melhores turmas, principalmente na primeira série, em que havia um maior número de professoras do município, realizou um sorteio para a distribuição dos professores. Todos os professores do município ficaram com as turmas mais difíceis. Estranhando esse resultado do sorteio, perguntamos aos que estavam envolvidos o que havia acontecido, e todos confirmaram que a distribuição tinha sido feita por sorteio. As professoras do município afirmaram: "Não tivemos sorte; ficamos com as turmas mais difíceis".

Verificamos que, apesar de as filiações institucionais serem diferentes, o objeto de disputa e, conseqüentemente, de reconhecimento continua sendo o mesmo: as melhores turmas.

Também a posse de cargos de gestão, principalmente a direção da escola, é objeto de concorrência e do uso de estratégias de desqualificação por parte dos professores, segundo sua filiação institucional. Quando a escola é gerida por uma diretora do estado, as professoras do município reclamam: "Aqui a diretora só dá feedbacks negativos para os professores do município. Dos professores do estado, 
ninguém chama a atenção" (Prof. MT 9). Quando a escola é gerida por uma diretora do município, as professoras do estado reclamam: "O município não informa as mudanças para nós. Somos sempre os últimos a saber e, quando ficamos sabendo, é, muitas vezes, fora da escola" (Prof. C 6).

Esse processo de municipalização também trouxe outras conseqüências: a insegurança maior por parte dos professores do estado, que, por estarem em adjunção ${ }^{3}$, dependem de uma avaliação da escola sobre sua permanência ou não no estabelecimento. Como o processo de avaliação formal não tem sido até então, nas escolas pesquisadas, um instrumento de análise do desempenho, os professores em adjunção afirmaram encontrar-se em uma posição delicada, pois, segundo eles, ficam sujeitos a uma avaliação informal que, normalmente, é muito mais sujeita a preferências e escolhas que escapam ao controle dos professores avaliados. Outra conseqüência é o maior enfraquecimento do sindicato, fato esse evidenciado pelo silêncio dos professores sobre a questão, mencionada por apenas uma das professoras entrevistadas e que lhe atribuiu uma importância decisiva em sua formação profissional (professora com 18 anos de experiência profissional).

A relação de concorrência mantida dentro dos estabelecimentos escolares parece refletir uma concorrência anterior entre os tipos de estabelecimentos - estadual ou municipal. Essas lutas por qualificar ou desqualificar o que seja escola estadual e escola municipal implicam a construção de uma classificação valorativa que acaba por dificultar a busca de um trabalho coletivo em prol da melhoria do sistema educacional como um todo.

\section{CONSIDERAÇÕES FINAIS}

As questões discutidas levam-nos a pensar na dificuldade de se mudar a forma como o professor é socializado profissionalmente. Segundo Dubar:

Querer fazer passar os indivíduos de uma forma identitária para outra constitui um objetivo muito ambicioso que lhe exige ao mesmo tempo que mude a configuração dos saberes e a relação vivida no trabalho. Se estes elementos não mudarem, há muito poucas hipóteses de a formação modificar quem quer que seja... (1997, p. 51)

3. A adjunção consiste em um contrato de trabalho pendente, renovável anualmente, mediante a aquiescência de ambas as partes contratadas, professor e prefeitura. Se uma das partes não for favorável à renovação do contrato de adjunção do professor, ele é colocado em disponibilidade para o estado, que poderá decidir como melhor lhe convier sua lotação em outro estabelecimento. 
Essa afirmação de Dubar faz-nos deparar com a dificuldade de a formação, por si só, modificar o processo de socialização profissional dos professores iniciantes. Também não nos parece adequado simplesmente modificar a matriz da trajetória profissional dos professores, delegando as turmas mais difíceis aos professores antigos, se não se repensarem as condições da socialização profissional oferecidas aos professores iniciantes: a forma de classificação das turmas, a distinção conferida pelo tempo de exercício profissional e a atribuição das melhores turmas aos professores mais antigos. Modificar a forma de classificação das turmas, aumentando sua heterogeneidade, poderia ser um tratamento precipitado se não se considerar a complexidade de uma pedagogia diferenciada, tão bem discutida por Perrenoud (2000). Além disso, como qualquer processo de mudança gera medos e resistências, a modificação simplesmente por decreto possivelmente acarretaria mais dificuldades que soluções.

Tais constatações nos conduzem aos limites desta pesquisa, cuja contribuição reside na importância de se considerar a organização escolar como um aspecto relevante para a compreensão da socialização profissional nessa etapa. Contudo, como o processo de pesquisa é um jogo de luzes e sombras, foi possível iluminar alguns aspectos desse processo, deixando outros para serem esclarecidos por outras investigações.

\section{REFERÊNCIAS BIBLIOGRÁFICAS}

BOURDIEU, P. Escritos de educação. 2. ed. Petrópolis: Vozes, 1998.

. O Poder simbólico. 2. ed. Rio de Janeiro: Bertrand Brasil, 1998a.

Razões práticas: sobre a teoria da ação. Campinas: Papirus, 1996.

As Regras da arte: gênese e estrutura do campo literário. São Paulo: Companhia das Letras, 1996a.

BRANDÃO, Z.; BAETA, A. M. B.; ROCHA, A. D. C. Evasão e repetência no Brasil: a escola em questão. 2. ed. Rio de Janeiro: Dois Pontos, 1986.

BRASIL. Leis de Diretrizes e Bases da Educação Nacional. São Paulo: Cortez, Ande, 1990.

CUNHA, M. I. O Bom professor e sua prática. Campinas: Papirus, 1989.

DUBAR, C. Formação, trabalho e identidades profissionais. In: CANÁRIO, R. (org.). Formação e situaçôes de trabalho. Portugal: Porto Editora, 1997. p. 43-52.

FREITAS, M. M. C. O Professor iniciante e suas estratégias de socialização. Rio de Janeiro, 2000. Dissert. (mestr.) PUC. 
GONÇALVES, J. A. M. A Carreira das professoras do ensino primário. In: NÓVOA, A. (org.). Vidas de professores. 2. ed. Portugal: Porto Editora, 1995. p. |4|-169.

GUARNIERI, M. R. Tornando-se professor: o início na carreira docente e a consolidação da profissão. São Carlos, 1996. Tese (dout.) Centro de Educação e Ciências Humanas/Universidade Federal de São Carlos.

HUBERMAN, M. O Ciclo de vida profissional dos professores. In: NÓVOA, A. (org.). Vidas de professores. 2. ed. Portugal: Porto Editora, 1995. p. 31-61.

KUZMIC, J. A Beginning teacher's search for meaning: teacher socialization, organizational literacy, and empowerment. Teaching \& Teacher Education, Great Britain, v. 10, n. I, p. I527, 1994.

LELIS, I. A. O Magistério como campo de contradições. Contemporaneidade e educação: revista semestral de Ciências Sociais e Educação, Rio de Janeiro, ano II, n. 2, p. I 43- I 55, set. 1997.

LÜDKE, M. O Educador: um profissional? In: CANDAU, V. M. Rumo a uma nova didática. 8. ed. Petrópolis: Vozes, 1996. p. 64-73.

. Formação inicial e construção da identidade profissional de professores de $1{ }^{\circ}$ grau. In: CANDAU, V. M. (org.). Magistério : construção cotidiana. Petrópolis: Vozes, 1997. p. I I0125.

Os Professores e sua socialização profissional. In: REALI, A. M. M. R.; MIZUKALLI, M. G. N. (orgs.). Formação de professores: tendências atuais. São Carlos: UFSCAR, Finep, 1996a. p. 26-46.

. Sobre a socialização profissional de professores. Cadernos de Pesquisa, São Paulo, n. 99, p. 5-15, nov. 1996 b.

. A Socialização profissional de professores. $3^{a}$ etapa: As Instituições Formadoras. Relatório de Pesquisa. Departamento de Educação, PUC-Rio, 1998.

LÜDKE, M.; MEDIANO, Z. D. A Socialização profissional de professores. Projeto de Pesquisa. Departamento de Educação, PUC-Rio, 1992.

A Socialização profissional de professores. Relatório de Pesquisa. Departamento de Educação, PUC-Rio, 1994.

MICHELAT, G. Sobre a utilização da entrevista não-diretiva em sociologia. In: THIOLLENT, M. (org.). Crítica metodológica, investigação social e enquete operária. 5. ed. São Paulo: Polis, 1987. p. |91-21।.

PERRENOUD, P. Pedagogia diferenciada: das intenções à ação. Porto Alegre: Artes Médicas Sul, 2000. 